\title{
A verdade como questão em A paixão segundo $G$. $H$., de Clarice Lispector
}

\author{
Ana Maria Ferreira Torres ${ }^{1}$ \\ Graduação em Letras da Universidade Federal do Pará \\ Antonio Maximo Gomes Ferraz ${ }^{2}$ \\ Universidade Federal do Pará
}

\begin{abstract}
Resumo: O trabalho pretende investigar como se dá o desvelamento da questão da verdade em A paixão segundo G.H., de Clarice Lispector. Entendemos que a obra literária é caracterizada pelo desvelar de questões ontológicas que não podem ser definidas, como, por exemplo, a vida, a morte, a liberdade, o bem, o mal, o destino e, na presente interpretação, a questão da verdade. Cada obra apresenta um pensamento originário das questões nela presentes. A personagem G. H. era acostumada à beleza dos acréscimos, como, por exemplo, os conceitos que formara para si, a fim de não precisar questionar-se. Ao encontrar uma barata em um quarto vazio de seu apartamento, G. H. é levada a questionar sua noção de verdade como correção e adequação do pensamento (correspondente à palavra grega orthotes e à palavra latina veritas) para considerar a verdade como desvelamento (correspondente ao termo grego aletheia). É esta mudança o que conduz a travessia da personagem. Utilizou-se como método a interpretação hermenêutico-fenomenológica da obra, ou seja, a leitura da obra a partir das questões que ela manifesta a partir de si mesma, evitando incorrer na aplicação de teorias prévias ao acontecer da própria arte. Dialogamos com pensadores tais como Martin Heidegger, Platão, Friedrich Nietzsche, entre outros.
\end{abstract}

Palavras-chave: A paixão segundo G.H. Questão. A verdade. O nada.

\section{A obra e a verdade}

A paixão segundo G.H., romance de Clarice Lispector, suscita questionamentos desde seu lançamento, em 1964. O romance é uma das principais obras da autora, recebendo destaque por parte de muitos críticos literários, entre eles, Luis Costa Lima, Benedito Nunes e Affonso Romano de Sant'Anna. Único romance em primeira pessoa de Clarice Lispector, sua escritura pouco convencional abre inúmeras possibilidades de interpretação. Nossa

\footnotetext{
${ }^{1}$ Estudante de graduação do curso de Letras, habilitação em Língua portuguesa, da Universidade Federal do Pará. Integrante do Núcleo Interdisciplinar Kairós - Estudos de Poética e Filosofia (NIK/UFPA).

${ }^{2}$ Professor Adjunto do Instituto de Letras e Comunicação da Universidade Federal do Pará e do Programa de Pós-Graduação em Letras na mesma Universidade. Doutor em Ciência da Literatura pela Universidade Federal do Rio de Janeiro, na área de Teoria Literária, com a tese "Fernando Pessoa em obra: a teatralização da metafísica". Mestre em Teoria Literária pela Universidade de Brasília, com a dissertação "O sagrado no 'Retábulo de Santa Joana Carolina', de Osman Lins". Bacharel em Direito pela UnB e advogado. É um dos coordenadores da Rede Poética - Grupo Interinstitucional de Pesquisas em Arte e Filosofia, grupo que reúne pesquisadores de diversas universidades brasileiras. Coordena o Núcleo Interdisciplinar Kairós - Estudos de Poética e Filosofia (NIK/UFPA).
} 
abordagem de A paixão segundo $G$. $H$. se faz por via da hermenêutica fenomenológica, ou seja, exercitando a escuta do sentido da obra a partir dela mesma. Como afirma Hans George Gadamer (2014):

Aquele que quer compreender não pode se entregar de antemão ao arbítrio de suas próprias opiniões prévias, ignorando a opinião do texto da maneira mais obstinada e consequente possível [...]. Em princípio, quem quer compreender um texto deve estar disposto a deixar que este lhe diga alguma coisa (GADAMER, 2014, p. 358).

Realizamos a escuta da obra por meio do desvelamento de suas questões, as quais consistem em indagações que a obra literária e as obras de arte como um todo dirigem ao homem, pois a ele dizem respeito: são questões ontológicas, portanto, que se dirigem a seu ser. O que são a vida, a morte, a liberdade, o amor, o bem, o mal, o belo, entre outras infinitas perguntas? Elas dizem respeito à vida de homens e mulheres de todas as épocas e de todos os lugares. Logo, a obra literária é vista aqui como um operar de questões (obra vem do latim opus, que também está na origem do verbo operar).

A paixão segundo G.H. não se limita a apenas uma questão. Porém, há uma pergunta que norteia todo o romance: o que é verdade? A personagem principal, G.H., que também é a narradora, após viver um momento aparentemente ordinário, no entanto, para ela, aterrador um encontro com uma barata em um quarto vazio -, passa a questionar aquilo em que acreditava como sendo a verdade. Por meio desse simples questionar, a vida de G.H. sofre uma reviravolta, fazendo-a retornar às origens da vida, despindo-se de todos os conceitos e atributos que formara para si, até chegar ao núcleo pré-humano da existência, cuja imagem é a barata. Nesta experiência, dá-se uma radical transformação de G.H.

Parece incoerente que a verdade, a qual, nos dias atuais, está sob domínio exclusivo da ciência, seja discutida em uma obra de ficção. Afinal, a literatura e as artes em geral são entendidas como imitação da realidade, tradução mais conhecida da palavra grega mímesis, expressão utilizada por Aristóteles em sua Arte Poética. Entretanto, mímesis também pode ser entendida como criação original. Antônio Jardim articula um entendimento diferente do usual ao pensar a mímesis, propondo que esta seja vista pelo gesto do ator desde o grego mimos: o gesto criador (apud GATTO, 2014, p. 155). Gesto é uma palavra oriunda do latim gestus, a qual foi tomada do grego gero, cujo significado é, entre outros, criar, produzir: gerar. Logo, a literatura não é mera imitação, mas criação. Toda literatura é poesia, não por comportar estrofes e versos, mas porque nela vigora a poiesis, palavra grega que diz agir, criar. A recorrência à etimologia não tem como objetivo, aqui, comprovar significados, mas buscar o sentido original de vocábulos carregados de questões, pois, como afirma Martin Heidegger, 
em A origem da obra de arte (2010), o sentido da palavra, em sua língua primeva, contém a experiência do povo que a criou. A experiência grega é levada, aqui, em conta não porque os gregos tenham sido uma civilização superior às outras, e, sim, porque sua linguagem forma a base da cultura e do pensamento filosófico ocidental. Por esse motivo, Heidegger e Friedrich Nietzsche buscaram a sabedoria grega dos pensadores originários, ditos, errônea e preconceituosamente, pré-socráticos. Eles não são "pré" nada. Toda obra de arte digna do nome - como a de Clarice, por exemplo, que estamos interpretando - é sempre uma experiência inaugural, e, por isso mesmo, jamais uma cópia de algo prévio.

Evitou-se a aplicação de teorias prévias acerca da leitura do romance, para que ele pudesse se manifestar a partir de si mesmo. Exercitamos, no entanto, o diálogo com obras de outros autores, entre elas, as de Heidegger, que provocou, desde a publicação de Ser e Tempo, uma verdadeira revolução no pensamento, seja filosófico, seja nos domínios da compreensão da arte.

\section{Da estética à verdade}

Como observa Luís Costa Lima (1969), a vida de G.H. é como a das outras personagens dos romances da escritora: "esquematicamente, a situação comum seria a seguinte: a vida cerca os personagens de conforto, a segurança do seu dia-a-dia domestica a potência agressiva do mundo" (COSTA LIMA, 1969, p.18). G.H. se considera uma pessoa independente, tem boas condições financeiras, exerce uma atividade agradável como escultora e tem boas relações sociais. É de se imaginar que "vivia bem, vivia bem, vivia bem" (LISPECTOR, 2009, p. 67).

G.H. priorizava acima de tudo o bom gosto e a beleza. Todavia, esses dois elementos, com seus desdobramentos (organização, limpeza, esperança, gosto, moral), no desenrolar da experiência da personagem passam a ter uma conotação negativa. Ou, ao menos, têm o seu significado radicalmente alterado.

Belo, para G.H., era a comodidade de não precisar se questionar, se autoconhecer, viver sem maiores inquietações. Em primeiro lugar, não perguntava "quem sou” e sim, "entre quais sou" (LISPECTOR, 2009, p. 27). Ela gostava de se ver como os outros a viam: "era o que os outros sempre me haviam visto ser, e assim eu me conhecia. Não sei dizer o que eu era" (LISPECTOR, 2009, p. 22-23). A autoimagem formada a partir dos conceitos exteriores também está no conto machadiano $O$ espelho. Neste, o personagem central é Jacobina, um 
Antonio Maximo Gomes Ferras

jovem promovido a alferes. Os mimos e carinhos que o jovem militar passa a receber, somente em virtude da patente, transformam o modo como ele vê a si mesmo. Começou a se perceber mais como o militar do que como homem - evidentemente, ser humano é mais do que ter uma forma humana, é questionar-se. Como diz Machado, o uniforme de alferes “matou o homem" (ASSIS, 1882, p. 99). A G.H. escultora, a G.H. que tinha um apartamento luxuoso em uma cobertura, e que vivia entre amigos, evadia-se da pergunta sobre quem ela era. Quando estava sozinha - oportunidade na qual talvez pudesse fazer essa pergunta -, "não havia uma queda, havia apenas um grau a menos daquilo que eu era com os outros, e isso sempre foi a minha [...] espécie de beleza" (LISPECTOR, 2009, p. 25). A personagem sacrificava a indagação sobre sua identidade para que o "bom gosto" a mantivesse em "boa sociedade".

G.H. temia o "estilhaçamento do silêncio" (LISPECTOR, 2009, p. 24). Tal silêncio era encontrado nos únicos momentos em que via a si própria: nas fotografias. Esse silêncio temido por G.H. não era apenas o silêncio da fala, mas se assemelha muito ao silêncio entendido por Heidegger: "Silêncio é a concentração e recolhimento de todo o comportamento, de maneira que este se atenha a si mesmo e, com isso, fique ligado em si" (HEIDEGGER, 2012, p. 123).

Para não ir ao encontro desse silêncio que a fizesse recolher-se em si mesma, indagando quem ela era, de verdade - para não se deixar por ele tomar -, G.H. se organizara até que sua identidade fosse ocultada por seu próprio nome: "o resto eram sempre as organizações de mim mesma [...]. Era o modo como pouco a pouco eu havia me transformado na pessoa que tem o meu nome. E acabei sendo o meu nome" (LISPECTOR, 2009, p. 24).

Entretanto, esse silêncio não apenas se refere ao conhecimento e ligação de cada ser humano consigo mesmo, mas com o "sendo em geral” (HEIDEGGER, 2012, p. 123), isto é, com a totalidade das coisas. G.H. tinha medo de ser parte do mundo, do real, da vida: "Há um mau gosto na desordem de viver" (LISPECTOR, 2009, p. 27). A personagem, então, embelezava o mundo para que ele não se revelasse como é, admitindo que preferia a cópia ao autêntico. A sua vida antiga não era "real": "Real eu não a entenderia, mas gosto da duplicata e a entendo. A cópia é sempre bonita" (LISPECTOR, 2009, p. 29). Ela preferia que o mundo não fosse dela para que não se encarregasse da responsabilidade de existir. A Beleza era o gatilho para escapar do Real e sua claridade - a claridade natural da existência: "a claridade natural do que existe, e é essa claridade natural o que me aterroriza" (LISPECTOR, 2009, p. 
17). Como entender essa "claridade" de que fala a obra? Compreende-se, aqui, que há uma relação entre a claridade citada na obra e a ideia de claridade que circulava entre os pensadores originários. Segundo Emmanuel Carneiro Leão, a Luz era considerada princípio de tudo, inclusive da arte, na Grécia antiga. Entretanto, não se tratava da Luz em oposição à Escuridão. A luminosidade era a "energia radiante em todo ser e não ser" (CARNEIRO LEÃO, 2011, p. 38). É a unidade que une todos, de acordo com Heráclito de Éfeso, que diz, no fragmento 50, que "tudo é um". A saga de G.H. nos informa que essa claridade é comum à toda vida. Do mesmo modo, a leitura de Benedito Nunes (2012) acerca da obra Einführung in die Metaphysik (Introdução à Metafísica), de Martin Heidegger, nos revela que, ao estudar o belo em Hegel e na arte grega, o pensador da Floresta Negra considera que surgir, vir à luz, é Ser. Não por outro motivo, G.H., antes da travessia que realizará, tem horror à claridade: ela tinha medo de simplesmente ser, sem enfeites. "Como é que se explica que o meu maior medo seja exatamente em relação: a ser?” (LISPECTOR, 2009, p. 11).

A Beleza à qual G.H. se subordinava, além de tirar-lhe a Liberdade, não tinha télos, ou seja, um sentido que conduzisse sua vida à plenitude. Nunca chegara à plenitude, pois tudo o que até então alcançara fora um "pré-clímax": "O pré-clímax foi talvez até agora a minha existência [...]. Eu nascera sem missão, minha natureza não me impunha nenhuma" (LISPECTOR, 2009, p. 27). A personagem sempre retardava seu autoquestionamento, baseando-se em uma esperança cujo significado para ela era apenas o de esperar, e não o de agir.

Logo, a beleza para G.H. tinha a função de camuflar e estetizar a vida, tornando-a uma cópia do real. Nisso há uma semelhança à natureza da arte como determinada pela estética, ou seja, como cópia e embelezamento da realidade. Tem-se a realidade estetizada segundo as determinações de gosto do sujeito, não a realidade ela própria. Lembremo-nos do que diz Alberto Caeiro, heterônimo de Fernando Pessoa: "O universo não é uma ideia minha/ A minha ideia do Universo é que é uma ideia minha" (PESSOA, 2005, p. 113). ${ }^{3}$

G. H. baseava sua vida nas verdades que a ela foram transmitidas por toda a sua existência, não se permitindo sobre elas refletir, muito menos sobre si mesma. Ficava restrita a representações, não se abria para o questionamento. A personagem não era independente

3 Nossa época, aliás, se acha presa a representações da realidade que vedam o acesso a seu manifestar a partir de si mesma. Isto se percebe na noção de realidade, compreendida como a verdade, determinada pelas ciências. $\mathrm{O}$ que a ciência diz que é a verdade passa a ser tomado como $a$ verdade. Segundo Gadamer, tal noção de verdade adviria de Immanuel Kant, em sua crítica do juízo: "com Kant, medimos a verdade do conhecimento com o conceito do conhecimento da ciência e com o conceito de realidade da ciência da natureza" (GADAMER, 2014, p. 150). 
como aparentava. Ela era cativa de uma série de conceitos que classificava como humanos: "A vida humanizada. Eu havia humanizado demais a vida" (LISPECTOR, 2009, p. 12). Humano, segundo a tradição metafísica, é o animal racional, e a personagem racionalizara sua existência. Ronaldes de Melo e Sousa (1997) classifica o mundo em que vivia G.H. como apolíneo. Essa consideração é muito pertinente, uma vez que Nietzsche, em $O$ nascimento da tragédia (1992), diz que o apolíneo é o mundo do belo e do sonho, bem como o das artes plásticas, incluindo, aí, a escultura, justamente o ofício de G. H.

A situação de G.H. assemelha-se à dos prisioneiros da caverna na doutrina de Platão acerca da verdade, contida no livro VII de A República. Neste livro, nos é narrada a história de prisioneiros que estão presos em uma caverna, acorrentados a hastes e obrigados a olhar para o fundo desde a infância. No fundo da caverna, os prisioneiros veem apenas as sombras das pessoas e objetos que passam pelo lado de fora. Os homens acorrentados não têm o conhecimento de que os seres verdadeiros passam por detrás deles, e tomam as sombras como verdade.

\section{O Nada como abertura questionante}

Esse estado fantasioso não duraria para sempre. Como diz a personagem, "a vida às vezes volta" (LISPECTOR, 2009, p. 69). Cedo ou tarde, G.H. teria de se deparar com o real. E ele não se deixaria mais conter em uma representação estética. Essa "volta" se inicia em uma manhã tranquila, um dia após a empregada da escultora, Janair, ter se demitido. Naquele dia, a narradora-personagem decidira limpar o quarto que Janair ocupava. Limpar era um prazer para a artista. Porém, para sua surpresa, o quartinho que era da empregada estava completamente limpo e praticamente vazio, não fosse um guarda-roupa e uma cama, bem como uma espécie de pintura rupestre na parede do cubículo. A nudez do quarto enfureceu G. $\mathrm{H}$.

Importa analisar o compartimento em questão. Segundo G.H., ele "divergia do resto do apartamento" e "era o oposto do que eu criara em minha casa, o oposto da suave beleza que resultara de meu talento de arrumar" (LISPECTOR, 2009, p. 41). Esse quarto é o que se poderia chamar de unheimlich, ou seja, não-familiar (heim: lar, casa; un-: prefixo negativo). Entretanto, o outro significado para heimlich é o secreto, o clandestino. Assim, o cubículo que ocupou anteriormente Janair é, ao mesmo tempo, unheimlich e heimlich: não-familiar e também clandestino, pois em tudo diferia da estetização e suposta elegância do apartamento 
de G.H. O quarto não tinha a regularidade espacial apolínea à qual se acostumara a personagem: "O quarto não era um quadrilátero regular: dois de seus ângulos eram ligeiramente mais abertos" (LISPECTOR, 2009, p. 37). Além disso, o compartimento parecia ter luz própria: "o sol não parecia vir de fora para dentro: lá era o próprio lugar do sol” (LISPECTOR, 2009, p. 42), ou seja, irradiava uma luz toda sua que, como visto anteriormente, é comum a toda vida. O quarto, deserto, era "o retrato de um estômago vazio" (LISPECTOR, 2009, p. 42) e os desenhos na parede (o contorno de um homem, uma mulher e um cão) eram grotescos ${ }^{4}$. Isso tudo era uma afronta ao bom gosto e à sensibilidade estética da personagem.

Se o aspecto vazio do quarto já irritou profundamente G.H., a aparição de uma barata, saída pela porta do guarda-roupa, a desestrutura por completo. Subitamente, todo o seu pretenso domínio apolíneo da vida sucumbe ao instinto dionisíaco: "pela primeira vez eu me sentia toda incumbida por um instinto" (LISPECTOR, 2009, p. 51). A barata era um ser vivo, "um animal sem beleza para as outras espécies" (LISPECTOR, 2009, p. 94). Vê-se que a escultora se depara, no encontro com a barata, com a vida sem enfeites e atributos.

Submetida a esse instinto, a escultora tenta matar o inseto, ataca-o. Eis o momento em que G.H. mergulha no abismo de sua existência, iniciando um fluxo de consciência que a levará ao núcleo infernal da vida. Núcleo porque é a origem de todas as coisas. É o próprio “coração selvagem” do primeiro romance de Clarice, Perto do coração selvagem (1943), ou o/a "Ele-Ela", do conto Onde estivestes de noite (1974), também da autora. Esse núcleo é infernal porque conduz "para dentro da Terra" (infernum), remonta ao pré-humano, independe da esperança: "O inexpressivo é o diabólico. Se a pessoa não estiver comprometida com a esperança, vive o demoníaco [...] o demoníaco é antes do humano" (LISPECTOR, 2009, p. 100). Renata Tavares (2012) apresenta um sentido de inferno que se relaciona com o sentido de núcleo:

Inferno é uma palavra formada por in e ferus. In é uma preposição latina que significa 'em', 'entre'. E ferus, o radical, vem de 'fero', levar conduzir. Inferno é o conduzir ao entre, ao estar cravado na dor, entre duas condições, entre Ser e não-Ser (TAVARES, 2012, p. 26).

O bom gosto não teme o mau gosto, e, sim, o gosto nulo. Como observa Gadamer: "O bom gosto é uma sensibilidade que evita tão naturalmente tudo que é chocante que, para quem

4 Acerca do grotesco, comenta Affonso de Sant'Anna (2013, p. 147-8): "como adiantou Wolfgang Kayser, o grotesco se caracteriza por uma mudança violenta no sistema provocando insegurança e instabilidade. No grotesco há a falência da ordem moral e do universo físico", comprovando-se que o grotesco se relaciona diretamente com a ruptura de um sistema. 
não tem gosto, sua reação se torna simplesmente incompreensível" (GADAMER, 2014, p. 767). O gosto nulo é o gosto de nada. É a este nada que G.H. chegara: "Eu chegara ao nada, e o nada era vivo e úmido" (LISPECTOR, 2009, p. 60). Este nada foge completamente à compreensão da personagem, pois, ao se deparar com ele, que se vela e é uma contínua e eterna questão, seus conceitos desgastados, baseados em sua tentativa de organizar e fundamentar a realidade, desabam como um edifício antigo: "No desmoronamento, toneladas caíram sobre toneladas [...]. As coisas haviam voltado a ser o que eram" (LISPECTOR, 2009, p. 68). No núcleo da vida, as diferenças entre homens e bichos são nulas, pois a verdade humana não faz sentido nele: "A verdade não faz sentido, a grandeza do mundo me encolhe" (LISPECTOR, 2009, p. 17). Por esse motivo, as coisas voltam a ser como antes, ou seja, antes da predicação humana sobre a natureza. O fascínio e a angústia da personagem se dão ao descobrir que seus conceitos sobre o mundo não eram a verdade única e absoluta:

O mundo havia reivindicado a sua própria realidade, e, como depois de uma catástrofe, a minha civilização acabara: eu era apenas um dado histórico. Tudo em mim fora reivindicado pelo começo. Eu passara a um primeiro plano primário, estava no silêncio dos ventos e na era de estanho e cobre na era primeira da vida. [...] a pior descoberta foi a de que o mundo não é humano, e de que não somos humanos (LISPECTOR, 2009, p. 68).

Ao afirmar que "não somos humanos", G.H. constata que mesmo o que se conceitua como humano é passível de mudança. Este vão aberto na realidade leva G.H. a cair em um abismo sem fundo, sem fundamento, este entendido como a razão, que determina o que é verdadeiro no pensamento da modernidade. Leibniz afirma que "Nihil est sine ratione"5 (LEIBNIZ apud CASTRO, 2014, p. 110), ou seja, no nada não há razão nem fundamento. $\mathrm{O}$ Nada não é um fundamento, mas uma abertura questionante, justamente aquela que a personagem procurava anteriormente evitar.

Assim, G.H., que estava sempre tentando se distanciar do caos da vida, mergulha, agora, no nada caótico da existência ${ }^{6}$. Esse mergulho provoca uma dor, dor essa escondida sob uma alegria dionisíaca: "Então havia chamado de alegria o meu mais profundo sofrimento" (LISPECTOR, 2009, p. 131), diz G.H. Assistimos a uma dor parecida na personagem Lóri, do romance, também da autora, Uma aprendizagem ou o livro dos prazeres, quando se sente cair no nada. Sobre isto, afirma Tavares: "É a dor que é a vida, pois é o mistério, o não saber e, primordialmente, o não saber o que fazer de si próprio" (TAVARES, 2012, p. 34). Nietzsche

5 "Nada é sem razão". Tradução de Manuel Antônio de Castro.

6 Sobre a relação entre caos e Clarice Lispector, Carlos Mendes de Sousa (2000) afirma: "Com Clarice Lispector, o movimento da escrita segue outras direcções que não as do susto e paralisia face à desordem; é no mergulho no próprio caos, e para lá da razão, que ela encontra as razões da sua criação, procurando que a sua escrita viva no seio da própria incompreensão" (MENDES DE SOUSA, 2000, p.109). 
considera que essa alegria nervosa faz parte do processo de libertação do espírito, quando ele se liberta das verdades a ele impostas: "eis o que há de ruim e doloroso na história do grande livramento. É, ao mesmo tempo, uma doença, que pode destruir o homem, essa primeira irrupção de força e vontade de autodeterminação" (NIETZSCHE, 1991, p. 43). Porém, essa dor prenuncia um reinício para G.H. Este recomeço se relaciona com o sentido gerador do caos. Jaa Torrano (2012), ao interpretar a Teogonia de Hesíodo, ou seja, a gênese mitológica grega, afirma que o Caos (do grego Khaos) é um dos quatro nomes do sujeito composto do verbo genet (nascer):

A simetria entre Caos, o primeiro dos quatro termos que compõem o sujeito do verbo génet', "nasceu", e Eros, o quarto termo desse sujeito composto, permite-nos entender Kháos como o nome da ação de entreabrir-se e fenderse [...]. A simetria entre Caos e Eros como nomes de ação permite-nos pensar que descrevem as duas formas de procriação pelas quais se desdobram as genealogias divinas da Teogonia, Caos nomeando a procriação por cissiparidade, e Eros nomeando a procriação por união amorosa (TORRANO, 2012, p. 32).

Estar diante desse nada caótico, o núcleo e, portanto, origem da vida e de tudo o que é (o ente ou o sendo), permitiu à personagem ver e sentir as próprias coisas, estar no mesmo patamar delas, o que antes não ocorria, pois ela, como humano predicador que era anteriormente, dependia dos conceitos e representações criados sobre a realidade.

Ao voltarmos ao mito da caverna de Platão, encontramos um dos prisioneiros cavernícolas em situação parecida com a de G.H. Depois de ser libertado de suas amarras e sair da caverna, pôde ver as coisas elas mesmas, não apenas suas sombras. E não tarda a perceber que vivia, antes, em uma realidade falseada.

No núcleo, as coisas voltaram a ser como eram, e G.H. pôde vê-las. Contudo, jamais poderia esgotá-las com uma definição humana, pois elas sempre se mantêm como enigmas:

Eu arriscara o mundo em busca da pergunta que é posterior à resposta. Uma resposta que continuava secreta, mesmo ao ser revelada a que pergunta ela correspondia. Eu não havia encontrado uma resposta humana ao enigma. Mas muito mais [...] encontrara o próprio enigma (LISPECTOR, 2009, p. 137).

Segundo Friedrich Nietzsche (1991), a série de conceitos que aceitamos como verdade não passa de metáforas que os humanos criaram, ao passar a realidade vivenciada para palavras. Logo, aquilo que veementemente se atesta como verdade inquestionável é uma ilusão e é mutável - portanto, não definível. Entretanto, os seres humanos se impõem a obrigação de aceitar tais verdades, assim como o fazia G. H. 


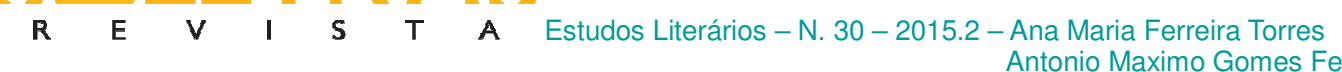

É como Santo Agostinho afirmou acerca da natureza do tempo: "Si nemo a me quaerat, scio, si quaerenti explicare velim, nescio" ("Se não me perguntarem, sei; se, perguntado, quiser explicar, não sei”). "É impossível definir o tempo. Tanto é assim que ele se manifesta em diferentes temporalidades" (FERRAZ, 2010, p. 2). A maneira de perceber o tempo no mundo ocidental atual não é a mesma como se percebia em outras eras.

Portanto, as coisas constituem, a partir desse momento, questões, pois nenhuma definição permite-nos cessar o interrogar. A própria escultora passará a se perceber como questão, convertendo-se em travessia contínua. Travessia, segundo Fabio Pessanha (2014), vem do latim trans-vertere, que é "o tornar-se no próprio que se é (vertere-) durante o percurso (trans-) da vida" (PESSANHA, 2014, p. 243). Depois da experiência que teve, G.H. afirma que "por não ser, eu era", "sem limite eu era" (LISPECTOR, 2009, p. 178). A personagem se concebe como um ser inacabado - uma incompletude que, antes de ser uma carência, é um convite à travessia existencial. G.H. nunca mais nunca cessaria de se tornar o que era: uma questão.

G.H supera a verdade à qual se submetera durante toda sua vida até então, abandona a "terceira perna" na qual sempre se apoiara - terceira perna que significa o apoio dos conceitos prontos e acabados, e que, no entanto, a impediam de caminhar, de fazer a travessia para si própria como questão. Ela se oferece à abertura do questionar das coisas, as quais, agora ela percebe, constituem enigmas: "a explicação de um enigma é a repetição do enigma" (LISPECTOR, 2009, p. 134). A realidade é, portanto, fonte inesgotável de questionamento. Esse questionar é a alétheia, palavra grega que queria dizer verdade. Verdade, para nós, vem do latim veritas, correção e adequação do pensamento, e nesta tradução perdeu-se o que a palavra grega evocava. Em grego, o termo alétheia significa o desvelar ou desencobrir das questões, que estão sempre veladas, ou seja, nunca são passíveis de serem contidas em uma definição, pois, quanto mais se desvelam, mas velam o que são.

Liberta dos conceitos, G.H. vê com outros olhos o tédio de viver, uma vez que já não sente necessidade dos acréscimos: "As coisas são muito delicadas. A gente pisa nelas com uma pata humana demais, com sentimentos demais" (LISPECTOR, 2009, p. 154). O tédio, o neutro da vida, é reconhecido como a felicidade do paraíso, não mais o inferno ${ }^{7}$. Diz G.H.: "Porque o tédio é uma felicidade primária demais! E é por isso que me é intolerável o paraíso. [...] Não estou à altura de ficar no paraíso porque [...] não tem gosto humano!” (LISPECTOR, 2009, p. 143). No tédio ela descobriu o amor e uma alegria contínua, alcançando o

7 Há no romance interessantes inversões, como o que é delicado (no início, a condição humana de G.H., no fim, o neutro vital) e o que é infernal (primeiramente, o nada é infernal, depois, é o paraíso). 
inexpressivo: "Amor neutro. Eu estava atingindo o que havia procurado a vida toda: aquilo que é a identidade mais última e que eu havia chamado de inexpressivo. [...] No neutro do amor está uma alegria contínua, como um barulho de folhas ao vento" (LISPECTOR, 2009, p. 133). A ânsia pelo inexpressivo a levou, inclusive, a um ato extremo: a manducação da barata morta - inseto este que, como em uma comunhão cristã, na qual a hóstia e o vinho são o corpo e o sangue de Deus, era o neutro, o insosso, o inexpressivo, o nada, a vida em si.

É desse modo que a escultora se despede da beleza: “Adeus beleza do mundo. Beleza que me é agora remota e que não quero mais" (LISPECTOR, 2009, p. 82). Ela se despe de tudo o que é atributo, como a própria esperança, que é, no caso do romance, somente a procrastinação: "Era já. Pela primeira vez na minha vida tratava-se plenamente de agora" (LISPECTOR, 2009, p. 79). Quanto à moral, diz ela: "De repente a questão moral me parecia não apenas esmagadora, como extremamente mesquinha” (LISPECTOR, 2009, p. 86). No âmbito de uma tal abertura, os valores demasiadamente humanos já não fazem mais sentido. Como pontua Heidegger, valorizar as coisas não é dar a elas sua merecida importância, mas subjugá-las ao juízo subjetivo dos homens: “Toda valorização [...] é uma subjetivação. Pois ela não deixa o ente ser, mas deixa apenas que o ente valha, como objeto de sua atividade" (HEIDEGGER, 1967, p. 78).

No último parágrafo do romance, G.H. pronuncia: "O mundo independia de mim" (LISPECTOR, 2009, p. 179). Ela e o resto dos humanos não mais possuem o controle sobre as coisas e todas as respostas sobre o mundo, não fazendo mais sentido assegurar verdades inquestionáveis, mas a eles cabe um constante desvelar das coisas. Os seis travessões grafados após a última oração, "E então adoro" (Idem), indicam uma infinitude, o que reforça a ideia desse contínuo desvelar que impele à travessia do questionamento.

\section{Travessia e paixão}

A travessia de G.H., embora intensa e radical, é a mesma a que todo homem e toda mulher estão convidados a realizar no decorrer de sua vida. Esta é movida pelas questões, e não pelas respostas. Entretanto, este questionar é sempre doloroso. Mas, da dor, pode vir a ascensão para uma forma mais plena de ser. A adolescência é uma fase angustiante e, ao mesmo tempo, decisiva, pois é a época em que o indivíduo mais se pergunta sobre si e sobre o mundo, abandonando muitas noções que as gerações anteriores lhe passaram. A história de Emil Sinclair, do romance Demian, de Hermann Hesse, narra esse conflito, quando o jovem 
Emil conhece o enigmático Demian, cujas ideias contrastavam com as que ele aprendera durante a infância com os pais e a religião, causando um grande impacto no protagonista do romance. Todavia, esse conflito positivo não se restringe a uma fase da vida. G.H., definitivamente, não era uma adolescente, uma vez que estava bem estabilizada financeiramente, já tivera casos com diversos homens, e, inclusive, já estivera grávida. Do romance, depreende-se que a escultora parece ser uma mulher de meia idade. Independentemente dos anos que contava, tendo em vista que cada um tem o seu kairós (o tempo oportuno, o tempo da maturação das questões), todo ser humano é essencialmente a abertura questionante para procurar o seu próprio, de maneira inaugural e autêntica.

A paixão de G.H., portanto, pode ser entendida como a travessia dolorosa que leva ao renascimento, assim como a de Cristo que, ao morrer na cruz, renasce para a eternidade. Para G.H., essa é a dor que teve de enfrentar para questionar suas antigas verdades. O homem não é o senhor do páthos (paixão). Ao contrário, ele é disponibilizado pelas paixões. Tanto é assim que ninguém decide se apaixonar. Para G.H., esta paixão é o deixar-se tomar pelas questões que já a questionavam - como a todos os homens -, mas que ela se recusava a escutar. Ao se permitir perguntar quem ela própria era, a verdade (aletheia) se desvela a G.H., convertendo sua existência em uma travessia que é essencialmente uma abertura para o questionar contínuo do sentido.

\section{Referências bibliográficas:}

ASSIS, Machado de. O espelho. In: __. Papéis avulsos. S. 1., Lombaerts \& C., 1882. Disponível em: <http://www.dominiopublico.gov.br/download/texto/bv000230.pdf> Acesso em: 16 jul. 2015.

CARNEIRO LEÃO, Emmanuel. A luz na arte grega. In: BOCAYÚVA, Izabela (Org.). Filosofia e arte na Grécia antiga. Rio de Janeiro: Nau: Hexis, 2011. p. 37-42.

CASTRO, Manuel Antônio de. Fundamento. In: . et al. Convite ao pensar. Rio de Janeiro: Tempo Brasileiro, 2014. p. 109-110.

GADAMER, Hans-Georg. Verdade e método: traços fundamentais de uma hermenêutica filosófica. Trad. Flávio Paulo Meurer. 14 ed. Petrópolis, RJ: Vozes, 2014.

GATTO, Eduardo. Mimesis. In: CASTRO, Manuel Antônio de... [et. al.] (Coord.) / (Org.). Convite ao pensar. Rio de Janeiro: Tempo Brasileiro, 2014. p. 155-156.

HEIDEGGER, Martin. A origem da obra de arte. Trad. Idalina Azevedo; Manuel Antônio de Castro. Edições 70, São Paulo, 2010.

Ser e Verdade. Trad. de Emmanuel Carneiro Leão. Petrópolis: Vozes; Bragança Paulista, SP: Editora Universitária São Francisco, 2012. 
. Carta sobre o humanismo. Trad. de Emmanuel Carneiro Leão. Rio de Janeiro: Tempo Brasileiro, 1967.

LIMA, Luís Costa. A mística ao revés de Clarice Lispector. In: Por que literatura. Petrópolis, RJ: Vozes, 1969.

LISPECTOR, Clarice. A paixão segundo G.H. Rio de Janeiro: Rocco, 2009.

NIETZSCHE, Friedrich. O Nascimento da Tragédia. Trad. J. Guinsburg. São Paulo: Companhia das Letras, 1992.

Humano, demasiado humano: um livro para espíritos livres. Primeiro volume (1878).

In: _. Obras incompletas. 5. ed. Trad. Rubens Rodrigues Torres Filho. São Paulo: Nova Cultural, 1991, p. 39-76. (Os Pensadores).

Sobre verdade e mentira. In: Obras incompletas. 5. ed. Trad. Rubens Rodrigues Torres Filho. São Paulo: Nova Cultural, 1991. p. 29-38. (Os Pensadores).

NUNES, Benedito. Passagem para o poético: filosofia e poesia em Heidegger. São Paulo: Edições Loyola, 2012.

PESSOA, Fernando. Poesia completa de Alberto Caeiro. São Paulo: Companhia das Letras, 2005.

PESSANHA, Fábio Santana. Travessia. In: CASTRO, Manuel Antônio de... [et. al.] (coord.)/(org.). Convite ao pensar. Rio de Janeiro: Tempo Brasileiro, 2014. p. 243-244.

SANT'ANNA, Affonso Romano de. O ritual epifânico do texto. In: COLASANTI, Marina. Com Clarice. São Paulo: Editora Unesp, 2013.

SOUSA, Carlos Mendes de. Clarice Lispector: Figuras da Escrita. Braga: Universidade do Minho; Centro de Estudos Humanísticos, 2000.

SOUZA, Ronaldes de Melo e. A poética dionisíaca de Clarice Lispector. In: Tempo Brasileiro, n. 130-131, Rio de Janeiro, Tempo Brasileiro, jul.-dez. 1997, pp. 123-143.

TAVARES, Renata. Do Silêncio à Liberdade: Uma Aprendizagem ou O Livro dos Prazeres. Rio de Janeiro: Tempo Brasileiro; União da Vitória, PRFAFIUV, 2012.

TORRANO, Jaa. A noção mítica de Kháos na Teogonia de Hesíodo. Ide, São Paulo, v. 54, n. 35, p. 29-38, jul. 2012.

Truth as a question in Clarice Lispector's A paixão segundo G.H

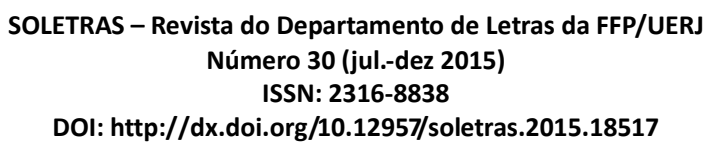


Abstract: This paper aims to investigate how is the question truth is unveiled in Clarice Lispector's A paixão segundo G.H. We understand that the literary work is characterized by the unveiling of ontological questions that cannot be defined, for example, life, death, freedom, good, evil, destiny, and in our case, the truth. Each work presents a original thought of the questions it presents. The character G. H. was used to the beauty of additions, for example, the concepts she had built for herself, in order not to need to question herself. When she finds a cockroach in an empty room of her apartment, however, G.H. is brought to question her notion of truth as correctness and adequacy of thought (corresponding to the greek word orthotes and to the latin word veritas) to consider the truth as disclosure (correspondent to the greek term aletheia). This is the change that leads the crossing of the character. It was used as method the phenomenological hermeneutic interpretation of the work, i.e. the reading of the literary work from the questions itself reveals, avoiding to resort to prior theories on the happening of the art itself. We dialogued with thinkers such as Martin Heidegger, Plato, Friedrich Nietzsche, among others.

Keywords: A paixão segundo G.H. Question. Truth. Nothingness.

Recebido em: 10 de setembro de 2015 .

Aprovado em: 24 de janeiro de 2016. 